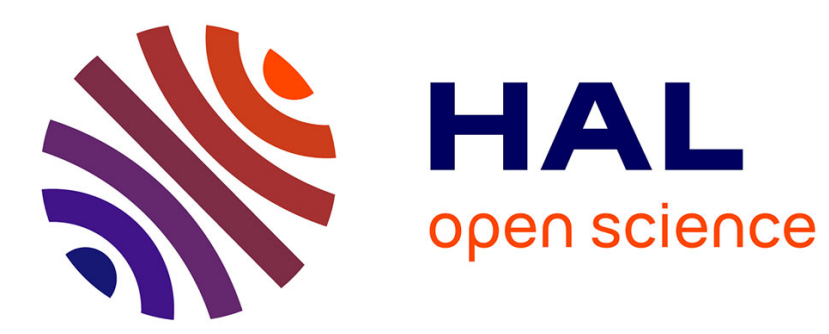

\title{
Does the discussion of socio-scientific issues require a paradigm shift in science teachers' thinking?
}

\author{
Stephen P. Day, Tom G.K. Bryce
}

\section{To cite this version:}

Stephen P. Day, Tom G.K. Bryce. Does the discussion of socio-scientific issues require a paradigm shift in science teachers' thinking?. International Journal of Science Education, 2010, pp.1. 10.1080/09500693.2010.519804 . hal-00639388

\section{HAL Id: hal-00639388 \\ https://hal.science/hal-00639388}

Submitted on 9 Nov 2011

HAL is a multi-disciplinary open access archive for the deposit and dissemination of scientific research documents, whether they are published or not. The documents may come from teaching and research institutions in France or abroad, or from public or private research centers.
L'archive ouverte pluridisciplinaire HAL, est destinée au dépôt et à la diffusion de documents scientifiques de niveau recherche, publiés ou non, émanant des établissements d'enseignement et de recherche français ou étrangers, des laboratoires publics ou privés. 


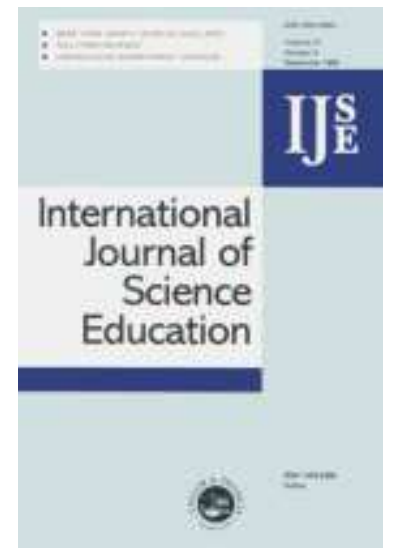

\section{Does the discussion of socio-scientific issues require a paradigm shift in science teachers' thinking?}

\begin{tabular}{|r|l|}
\hline Journal: & International Journal of Science Education \\
\hline Manuscript ID: & TSED-2010-0179.R1 \\
\hline Manuscript Type: & Research Paper \\
\hline Keywords: & $\begin{array}{l}\text { science education, qualitative research, scientific literacy, teacher } \\
\text { actions, discourse }\end{array}$ \\
\hline Keywords (user): & Discussion, Socio-scientific issues, In-depth teacher interviews \\
\hline \multicolumn{2}{|l}{} \\
\hline
\end{tabular}

\section{SCHOLARONE Manuscripts}




\title{
Does the discussion of socio-scientific issues require a paradigm shift in science teachers' thinking?
}

\begin{abstract}
The purpose of this study was to characterise secondary school science teachers' conceptual models of discussion, against the background that a number of researchers have found that discussion of socio-scientific issues in science classrooms is rare, somewhat discomforting for teachers and its purpose unclear. Recent research indicates that when science teachers do engage in socio-scientific discussion, the quality is poor and is teacher-centred where pupils' views do not figure prominently (far less be clarified and integrated with their scientific learning). This has led to calls for such dialogue to be conducted by humanities teachers. The question arising from such thinking is: Do science teachers hold different conceptual models of discussion from their humanities colleagues? Using semi-structured interviews, three groups each of six teachers (experienced science teachers, experienced humanities teachers, and newly qualified science teachers) were interviewed in depth in order to characterise their conceptual understanding of discussion as a teaching strategy. Analysis of the interview transcripts utilised the constant comparison approach of grounded theory. Five conceptual models of discussion emerged from an analysis of the data - discussion (i) as teachermediated discourse; (ii) as open-ended inquiry; (iii) for the development of reasoning skills; (iv) as mediated transfer of knowledge to real-life contexts; and (v) as practice for democratic citizenship. The results confirmed that the science teachers' emphasis tended to stress practice for democratic citizenship whereas the humanities teachers' emphasis was more towards open-ended inquiry and for the development of reasoning skills.
\end{abstract}




\section{Introduction.}

The science curriculum in Scotland is in the throes of reform under the auspices of a new national initiative known as Curriculum for Excellence $(C f E)$. Integral to the new science curriculum is classroom discussion of controversial socio-scientific issues as part of a Topical Science strand. It is hoped that by re-invigorating content and teaching strategies to link school science to the science which pupils hear about outside of school, the new curriculum will broaden its appeal and tackle the fairly widespread disengagement evident in schools (including gender inequities). Teachers use the term discussion to describe a multitude of different types of classroom discourse, for example: conversation, debate, dialogue, argument, etc... At the heart of these are ways to orally explore and critique consensus views. By doing so, learners develop a greater appreciation for the multiplicity of human knowledge and experience. In a discussion, the learner should feel that his/her views are valued and welcomed but that these views are open to analysis. Discussion is therefore defined here as the serious effort taken by a group of two or more individuals, in turns, to share and engage in mutual and reciprocal critique, the purposes of which are to help them to reach a more critically informed understanding of an issue; to enhance their self-awareness and capacity for self-reflection and self-critique; to encourage an appreciation among discussants for the diversity of opinion that might emerge when individual points of view are shared openly and honestly; and, to act as a catalyst to help the discussants to take informed action regarding the issue under discussion (c.f. Brookfield \& Preskill, 2005).

In common with a number of other countries, the use of discussion by Scottish science teachers is presently limited. Indeed a number of recent studies have shown that while science teachers understand that discussions within the context of science are useful, they fail to see their purpose and report that they are generally uncomfortable leading them (Author, 2004; Levinson \& Turner, 2001; Millar \& Osborne, 1998). 
In England and Wales, under the sponsorship of The Nuffield Foundation, an AS level course called Science for Public Understanding (SPU) was designed in partnership with the University of York in 1999. This course, implemented in 2000 and evaluated by Kings College London between September 2001 and April 2002 (Osborne, Duschl, \& Fairbrother, 2002), represented a step forward in curriculum design for the promotion of scientific literacy as, from the outset, this course deliberately contained scope for discussion of socio-scientific issues arising from contemporary science. In their evaluation report Breaking the Mould? Teaching Science for Public Understanding, Osborne et al. (2002) suggested that many of the lessons which involved discussion were of poor quality as evidenced from their observation of the teaching of discussion of socio-scientific issues contained within this AS level course, a sentiment exemplified by the following statement:

The first and most noticeable feature of these lessons was the dominance of classroom discourse by the teachers. Time and time again, it was the teachers who were observed to initiate the discourse in the classroom, controlling its form, and possibly its function, by using predominantly discourse strategies in which the teacher initiated discussion by asking a question (often closed), seeking a response and then providing an evaluative response that indicates to the student and the class whether their answer is correct or not (Osborne et al., 2002).

Osborne et al. went on to comment that this observation is unexceptional, when placed in context, since it is the teacher's responsibility to initiate and control the learning activities in the classroom but that it was surprising that so much of the dialogue took this form. In addition, they justified this comment by indicating that analysis of the case study data provided in the report showed 76 instances where such types of discourse were noted and went on to state:

It is surprising because one of the primary aims of the SPU course is for students to 'develop, and be able to express, an informed personal point of view on issues 
concerning science and technology'. It is hard to see, therefore, how this aim can be achieved when insufficient space is provided for students to develop such capabilities by opening up the nature of the discourse in the classroom to make it more of a genuine dialogue (ibid. p. 27).

The tone of this comment suggests that the teachers who took part in the research and who taught this course required help to develop pedagogical skills which would improve the quality of discussion as a teaching and learning strategy within their practice. This comment has been echoed in a number of studies which deal with such classroom dialogue (Author, 2004; Hodson, 1999; Hodson, 2003; Levinson, 2001; Levinson, 2003; Levinson et al., 2001; Millar et al., 1998; Oulton, Dillon, \& Grace, 2004; Reiss, 1999; Sadler, 2004a; Sadler, 2004b).

In their recent review of the research evidence concerning the use of small group discussions in particular in science teaching, Bennett et al. (2010) conclude that groups function best when differing views are represented amongst the students concerned and where they receive training in effective group work. To that end, the authors state: “... it is also clear that small group discussion work needs to be supported by the provision of support and guidance for teachers and students on the development of the skills necessary to make such work effective" (Bennett, Hogarth, Lubben, Campbell, \& Robinson, 2010).

Although in their report Osborne et al. did not probe the teachers' understanding of what discussion was in their evaluation of the SPU course, their conclusion that its quality within the lessons that they observed was poor begs some deeper questions: Do science teachers hold a poor conceptual understanding of what discussion is? Do they know what the purpose of discussion is? Osborne et al. defend the teachers by suggesting that: 
... the best explanation for these findings is that science teachers and their actions are structured by the nature of the agency they serve: science education, a practice which has been characterised as the last authoritarian socio-intellectual discipline (Ravetz, 2002). ...much of the teaching of science requires the teaching of consensually, well-established knowledge which is uncontroversial and not open to challenge or questioning. Consequently, science teachers tend to adopt a style which attempts to persuade their students of the validity of the scientific worldview and construct for themselves the entities that populate the scientific universe. The result is a dialogue which tends to be closed and authoritative. The normal daily practice of the science teacher does not provide many opportunities for the kind of interpretive and open discussion that the English teacher or History teacher might encourage (ibid p. 29).

The suggestion that humanities teachers are better equipped to deal with open discussion is a view shared by Levinson (Levinson, 2001; Levinson, 2003; Levinson et al., 2001). Furthermore, research suggests that humanities teachers hold multiple conceptual models of discussion (Larson, 2000; Parker \& Hess, 2001). However, Alvermann et al. (1990) has shown that, although humanities teachers could articulate abstract definitions of a good discussion, their enacted discussions seldom resembled these definitions. The teachers, due to perceived pressure from outside forces, were more concerned with maintaining control and covering content than with encouraging active participation from students in constructing meaning (Alvermann, O'Brien, \& Dillon, 1990).

On the face of it, the suggestion that science teachers need more opportunities to observe experienced humanities teachers to see the models, strategies and approaches they employ to foster and stimulate discussion, seems to be a good idea. However, this might potentially lead to problems since Alvermann et al. (1990) also suggest that teachers' conceptual understandings of discussion 
do not necessarily lead to better planning and execution of that dialogue in the classroom. Additionally, other research on discussion in social studies has shown that, when observed, social studies teachers (the American equivalent of the UK humanities teacher) only used discussion in $10 \%$ of their lessons and that when they did it was of poor quality, short in duration and teacher dominated (Hess, 2004; Nystrand, Gamoran, \& Carbonaro, 1998).

A search of the research literature in this field shows that there have been relatively few studies on the actual management of teaching using discussion. However, related research on the promotion of argumentation in science and teaching using controversial issues in science (Cross \& Price, 1996; Dawson \& Venville, 2010; Simon, Erduran, \& Osborne, 2006) does provide useful insights into the place of argumentation and disagreement within discussion. In fact, most of the literature on discussion in science pertains to the content complexities of the socio-scientific issues but interestingly fails to deal with the issue of whether the discussion was open or teacher dominated.

After a comprehensive literature search, not a single research paper dealing directly with the question of whether science teachers hold different conceptual models of discussion when compared to those of humanities teachers could be found. One paper that did observe both science and humanities teachers conducting what they reported to be discussion with their classes showed that even when observing social science, English, languages and art teachers handling dialogue, $40 \%$ of the observed lessons formed an open forum for discussion, with $60 \%$ of the lessons taking the form of either recitation or a lecture or a mixture of both (Alvermann et al., 1990).

What the Hess (2004), Nystrand et al. (1998) and Alvermann et al. (1990) studies show is that even humanities teachers have trouble teaching using discussion. In order to understand the root of such disparities we need to take a closer look at the nature of discussion and to research why teachers who can articulate their conceptual understanding of it, fail to enact genuine discussion when they claim to use it frequently. Furthermore, understanding science teachers' thinking, in particular about 
discussion, is required if we can assume that, as with all teachers, their thoughts underlie their classroom action (Clark \& Peterson, 1986). If discussion is to be used to help develop pupils' scientific literacy through engaging them in the process of discussing issues of a socio-scientific nature, then teachers are a crucial variable in creating the necessary context.

If teachers only think of discussion as a recitative interaction between teacher and pupil, then recommendations for the increased use of it are likely to fail. There is a clear need for additional insights into the uses of discussion particularly within the science classroom. This train of thought provides a focus for research, especially since the new science curriculum as set out by $C f E$ explicitly prescribes the discussion of socio-scientific issues within Scottish science education.

The aim of this research was to answer the following research questions:

1. Do science teachers hold different conceptual understandings of what discussion is compared to their humanities colleagues?

2. What do they know about the purpose of discussion?

3. How comfortable are science teachers when teaching using discussion of controversial socio-scientific issues and does this differ from humanities teachers?

\section{Methodology.}

The research methodology chosen for this study was a case study approach, the research questions requiring an in-depth qualitative analysis for the problems being explored. Data was gathered from semi-structured interviews with each of 18 teachers working in a large Scottish comprehensive secondary school (pupil population $=1336$ with a teacher population of 92). These interviews were conducted as part of a large action research project focusing on the increased use of socio-scientific discussion in science classrooms as part of that department's drive towards implementing the new science curriculum, as outlined under Curriculum for Excellence. The interviews were audiotaped 
and transcribed for future qualitative analysis. The teachers fell into three groups of six: experienced science teachers, newly qualified probationary science teachers, and experienced humanities teachers. All the participants were teachers within the same secondary (high) school where the first author also taught. The sample was not random since all of the participants worked either within the Science department of the school or, in the case of the humanities teacher group, worked within the Religious and Moral Education, Geography/History or English departments of the school. According to a recent (2006) HMIe inspection of the school, demographic indicators (like entitlements to free school meals, attendance and achievement rates) are close to the Scottish national average, indicating that the school could be fairly described as typical of Scottish secondary schools. The location was a small town in the Central Belt of Scotland and pupil attitudes to science closely corresponded to those obtained nationally as part of the international Relevance of Science Education (ROSE) survey (Farmer, Finlayson, Kibble, \& Roach, 2006).

\section{Teacher Backgrounds}

All the participants volunteered to take part in the study. The experienced science and humanities teachers had at least five years teaching experience and had taught all year groups and levels from first year secondary S1 (11-12 year olds) Science up to S5/6 (16-18 year olds) Higher and S6 (17-18 year olds) Advanced Higher in their respective subject disciplines. The mean \pm standard deviation age of the experienced science teachers group was $42.5 \pm 11.4$ years with a mean of 16.5 years of teaching experience; the mean age of the experienced humanities teachers group being $39.8 \pm 15.87$ years with 15.7 years of teaching experience. The newly qualified probationary science teachers were in their first teaching post within the school and had responsibilities for the teaching of Science for S1 and S2 (12-14 year olds) as well as either Intermediate Level One and/or Standard Grade classes in S3 (13-15 year olds) and S4 (14-16 year olds). The mean age of this group was $23.2 \pm 0.4$ years with a teaching experience of 1.2 years. The coding used in the findings section which follows are: ExST $=$ Experienced science teachers; ExHT= Experienced humanities teachers; 
NQST $=$ Newly Qualified science teachers. The Appendix provides biographical notes about the teachers involved in this study. Collectively, they underline the typicality of school staffing, their qualifications and teaching experience in Scottish secondary schools. Given what we know about differences between expert and novice teachers, it was considered important to include the newly qualified teachers in the research. In the light of likely differences in both pedagogical content knowledge and, in particular, pedagogical context knowledge (see Barnett and Hodson, 2006), their views of discussing controversial issues would be important. All participants were asked a series of common questions to elucidate the conceptual models of discussion which they held. These common questions were as follows:

- What is your understanding of what class discussion is? Prompt: Give specific illustrations or images of discussion, either experienced or observed which exemplify characteristics important to discussion.

- Can you describe an ideal discussion? Prompt: Focus on specific events within an ideal discussion.

- Can you give a description of an unsuccessful discussion?

- Can you list classroom activities which you use or could be used which incorporate discussion?

- What do you think the educational purpose of discussion is?

- How comfortable do you feel teaching using socio-scientific discussion?

\section{Data analysis of teachers' semi-structured interviews}

The method of analysis of the interview data utilised the constant comparative approach from grounded theory where the analysis of the data consisted of four stages. In the first stage, 36 categories were generated by reading the interview transcripts while listening to the taped interviews in an attempt to identify common themes. This stage was the constructive phase of data 
analysis. The second stage involved the integration of the categories and their properties by comparing similarities and differences among the categories created in stage one. The third stage involved integrating the data around fewer, more encompassing categories which meant that new categories had to be created, these refined and sharpened, and existing categories further elaborated. However, this process was not linear; rather the steps formed an iterative process of coding, comparing and refining (Glaser \& Strauss, 1967) to form a rich description of what these science and humanities teachers' conceptions were.

\section{Findings.}

The responses to each of the core questions formed the basis for generating the models of discussion as described by this group of teachers. These responses also allowed for qualitative differences to be seen between each of the three groups. However, the conceptual models described below were derived from the analysis of all the semi-structured interviews, allowing for a full spectrum of teacher views to shape the theory-forming phase of the analysis. It is worth reemphasising that the very nature of this case study meant that direct observations of the teaching were not made; we cannot claim that what teachers stated about their own practice is the same as what they actually do in the classroom. Nevertheless, as with all in-depth interviewing concerning teachers' understandings, the research does provide insights into the probable character of their interactions with the young people whom they teach.

\section{Teachers' conceptual models of discussion}

During the analysis, it became clear that teachers from different subject disciplines viewed discussion in a variety of different ways. Upon reading the interview transcripts, while listening repeatedly to the audio-tapes, it became evident that the teachers held a number of distinguishable ideas concerning discussion. However, the experienced humanities teachers were better able to articulate their models compared to their science colleagues. When reflecting on the interview 
transcripts, it was apparent that this group of science teachers struggled to verbalise what their understanding of discussion was. When directly questioned, most of them required extensive prompting and subsidiary questioning in order to fully explain their ideas about it. The data revealed that the eighteen teachers interviewed overall held five distinct models of discussion. These emerged from the process of refinement using the transcripts. The emergent models were: discussion (i) as a teacher-mediated discourse; (ii) as open-ended inquiry; (iii) for the development of reasoning skills; (iv) as mediated transfer of knowledge to real-life contexts; (v) as practice for democratic citizenship.

The constituent characteristics reveal that there were differences between the three groups in terms of the percentage of teachers who mentioned a particular characteristic of discussion when asked to describe what the educational purpose was (See Table 1). This shows that all the humanities teachers saw discussion as a way to develop pupils' thinking skills compared to only one third of experienced science teachers and half of newly qualified science teachers. However, 5 out of 6 experienced science teachers and 4 out of 6 newly qualified science teachers saw discussion as a way to develop social skills. Furthermore, 4 out of 6 experienced humanities teachers and half of experienced science teachers saw discussion as a way to expose pupils to multiple perspectives. Worryingly, only one out of the twelve science teachers and only half of the experienced humanities teachers saw discussion as a way in which pupils could formulate their own opinions.

\section{[Insert Table 1 about here]}

At this point it must be conceded that Table 1 represents a relatively crude method of identifying differences between the three different groups of teachers. Furthermore, just because a teacher does not mention a particular characteristic explicitly when asked does not mean that $\mathrm{s} /$ he views that characteristic as unimportant. It is possible that an omission may be due to the teacher seeing one characteristic as more important than another. For example, humanities teachers might see the 
development of social skills as unimportant since they may take them for granted, so do not mention their development explicitly when asked. Over the next five subsections, the different conceptual models of discussion will be described along with exemplar quotations from the interview transcripts.

\section{Discussion as a teacher-mediated discourse \\ Discussion as a teacher-mediated discourse could be described as a way in which teachers see discussion as a dialogue which they lead or control. With this model there is more pupil-to-pupil interaction than in a recitation style lesson. It also is conducted for a different purpose. For example, recitation is about questioning for the review of taught knowledge, whereas teacher-mediated discourse is intended to help pupils understand multiple perspectives which impinge on an issue being discussed in order to encourage a deeper understanding of the topic. This is exemplified by a comment from Experienced Humanities Teacher participant 2 (abbreviated as ExHT2):}

ExHT2: You get to draw things out of them [the pupils]. My job is to challenge the initial response and say 'well, let's look a little bit deeper' ... see things from another's perspective, so it's a kind of discovering things through, in a way, a metaphor. For example a metaphor can put things across in a way which say " $x$ " statements can't, so sometimes a discussion is a good way of getting them to engage with an issue that they don't necessarily get first off and, you know, this gives them confidence in their own opinions and you can improve your relationship with them and make them aware that maybe people don't always agree but that there are many different ways to look at the same issue and discussion is good for that.

What this statement shows is that the use of higher order questioning is employed by the teacher to elicit deeper responses from the pupils to the line of inquiry in the discussion. Teacher mediated 
questioning allows more than one perspective to be introduced, either from the pupils themselves or by the teacher. This model also allows the pupils to engage with an issue by providing a forum of views which they can follow in the context of the discussion. Thus the teacher is leading the pupils through the discussion to reach predetermined learning objectives while allowing pupils to interact more freely. This free interaction allows pupil-to-pupil and pupil-to-teacher interactions to flow during the discussion under the teacher's direction.

The teacher's role is seen as that of a facilitator. ExST1 and 4 exemplify this by suggesting that;

ExST1: ... the teacher is really just facilitating, not necessarily giving their point of view but really trying to gather from the class what their ideas are.

ExST4: Sometimes as a teacher it's your job to facilitate them and explain it to the rest of the class 'what they mean by that is ...' If they can't quite express it themselves they're still coming up with the original idea and concept themselves.

The idea that the teacher helps to reflect and rephrase pupils' comments suggests that in this model the teacher is helping to clarify pupils' views and opinions in order to help the class understand points which may have been poorly communicated by a pupil. This suggests that the teacher is modelling communication skills which the pupils may wish to adopt. During this kind of discussion the teacher is an active participant whereby s/he moderates and directs the flow of interactions and thus maintains order. However, in this model the teacher is leading the discussion by directing and posing questions which are designed to expose the pupils to multiple perspectives, where the pupil often responds to both teacher-posed and pupil-posed questions. The teacher may or may not give feedback on the pupils' responses but the teacher's role in this kind of discussion is pivotal in shaping its direction and pace. 


\section{Discussion as open-ended inquiry}

Discussion as open-ended inquiry is a model that teachers use to allow the discussion to flow, and where they do not always direct it or evaluate pupils' responses. In this model the teacher interacts orally with their pupils as a participant, where both teacher and pupils offer their own opinions on the issue under discussion. The teacher is not there to maintain control of the discussion but acts as both a guide and possibly even a learner.

Full participation is encouraged and expected. Experienced Science Teacher participant 2 suggests that:

ExST2: It's got to be a conversation where everyone in class, no matter what their ability, is able to get involved, at some level and also it's got to be so that they would actually feel confident and comfortable contributing something no matter what it would be.

This type of discussion can often turn out to be argumentative in nature. It generally occurs when the issue being discussed is controversial in nature or when the knowledge pertinent to such discussion is tentative or contentious in nature. In addition, issues which contain widely varying perspectives lend themselves to this type of discussion. For example, Newly Qualified Science Teacher participant 2:

NQST2: I would think that discussion from a science teacher's point of view is about the pupils trying to look at evidence and forming their own opinions based on the evidence, and being able to argue for and against their point.

By engaging with their pupils in this way the teacher is modelling how to participate in open-ended inquiry. This model of discussion is facilitated by the provision of a safe and trusting environment in which pupils talk about the issue in focus. As such issues tend to have with no clear or set 
ExHT1: When we do medical ethics we have them in groups and they discuss a moral dilemma and they have to decide what they thought the doctor should do ... Should they let someone continue to live in a certain state or should they allow them to die? They then have to collaborate with each other and come up with ideas and arguments for and against, to see if there was any consensus within the group.

This suggests that in this model of discussion, being prepared to be open minded and willing to look at all the pros and cons of an issue is integral to its success. However, it is important that in openended inquiry the discussion is focused on a particular concept, an issue or question. ExHT3 extends this idea as follows:

ExHT3: We ask a question and we expect a variety of responses so, for example, you're asking a question on transport and congestion then the solutions also have 
a lot of problems associated with them. So what you'd expect is for the discussion to develop an answer which dovetails into all the problems associated as well, where they can then bounce their ideas off each other.

In this regard, ExHT3 is suggesting that open-ended dialogue is about helping to tease out the complexity of the issue being discussed in order to expose the pupils involved to the complexity of the issue and to the problems associated with finding an acceptable solution. This model exposes pupils to the difficulties faced by people charged with coming up with solutions to everyday problems.

Discussion for the development of reasoning skills

In this model of discussion the teacher frequently uses critical questioning in an effort to challenge pupils' opinions, ideas or beliefs. This model differs from recitation as the teacher is not seeking particular answers to questions posed but is concerned with deliberately challenging pupils' thinking. In addition, it differs from open-ended inquiry in that the teacher continues to ask specific questions for different purposes, such as requesting clarification of pupils' views or asking for more information, or by opening up a different perspective by posing a question. This can also be used to develop or challenge pupils' thinking or can be used to provoke a reaction from them. This view is exemplified by the comment below from Experienced Science Teacher participant 3:

ExST3: Classroom discussion is... looking at possible misconceptions and asking pupils to discuss them with each other and raise them in a forum from the class, so that you can take what they have got and understand what they can do with it and where it's going. Challenge is the job of the teacher. To challenge what they have, be it a misconception or not, so that they can build on it in a productive way. Now misconceptions fall down either because other people in the class, ideally, or the teacher, will bring up a point whereby their logic falters 
and fails or you're testing their previous knowledge against each other and against the situation that the teacher introduces to see if it works. What you're looking for is the best possible construct between the pupils and the teacher. The teacher might add to things that the pupils have introduced that the teacher might not have thought of [before]. At the end of it what you've got is a forum of discussion whereby the best of all ideas come together and part of that is burning bridges that should not have been built in kids' minds based on complete fallacies.

ExST3 clearly feels that challenging misconceptions is best done through persuasion and logical argument using views from across the spectrum of the class. However, he also suggests that the role of the teacher in this is to stimulate and challenge the pupils' thinking. He also implies that there must be open-mindedness and a willingness to take on board other views both from the teacher as well as from other pupils. There must be curiosity on the part of pupils to engage and seek more information.

ExST3 put this view in the following terms:

ExST3: You have to have enough character to be able to put up an argument and be able to accept the fact that it doesn't go as well as they thought or it doesn't work at all. But still have the curiosity and interest and the investment amongst other people to feel it's still worthwhile to take part.

In this model, the teacher may adopt a 'devil's advocate' approach by questioning everything that is said. This is useful when the teacher detects that their pupils are biased or only have a shallow understanding of the issue under discussion which may lead to an opinion which is based on poor or weak reasoning. In order to stimulate pupils into questioning their own thinking, some teachers 
employ the deliberate tactic of making extreme statements designed to play on the pupils' values and their personal interpretations. This provokes a reaction which may increase pupil engagement in the discussion by touching a raw nerve as exemplified in the following extract from a male Experienced Humanities Teacher's interview (participant 4) below:

ExHT4: Typically when we are doing the Scottish Wars of Independence, what I am trying to do is burst the 'Braveheart' bubble, so I am trying to provoke people into discussion by calling William Wallace the English Osama bin Laden and get them to discuss that. That usually riles people, so I am trying to get them to discuss their perceptions of this important man... I've got to be, if you like, an agent provocateur to get them to participate. I've got to make a ridiculous statement like, if I am doing votes for women, to provoke the girls into a reaction I'll say: This is where it all went downhill, the end of civilisation as we know it when women started getting the vote. If I do that it provokes a response and I get more, wider perspectives.

This statement suggests that sometimes it is necessary for the teacher to take an extreme standpoint in order to stimulate the pupils into expressing points of view. However, this approach leads to a degree of unpredictability and potential loss of control over the direction of the discussion, depending on the views expressed.

ExST3: I don't think it [discussion] can be completely predictable from the start. It's organic, it is evolutionary and it has to be based on where they (the pupils) are coming from. The teacher has to get inside their logic and follow their logic to a point where it's defeated if it's no good or it's added to, to supplement the class knowledge if it is useful. 
This model also allows teachers to develop the pupils' reasoning skills by questioning their thinking through the use of counter-balancing questions, thereby helping pupils to question themselves. This process may stimulate them to reflect on their reasons for thinking the way they do, thus stimulating meta-cognition. This is exemplified by the following statement:

ExHT3: My role will be to ... Say they give you an answer to a problem, I'd say: 'Very good that is a good solution to that problem, but what are the issues which arise from this solution?' Hopefully to try and get them to think about the other issues surrounding the problem being discussed. So it's to get them to give us all their ideas on that one particular area with myself leading them through the complexities in different directions.

The main aim of this version is to stimulate pupil thinking and to challenge rather than direct their reasoning. However, this model is also aimed at developing other skills such as listening skills as well as confidence building.

ExHT6: Within the classroom, discussion is a way of allowing the pupils to think out loud ... They think out loud with other people and can hear what other people are saying, so it develops thinking skills; it develops their oral skills and their listening skills ... They may say something that sparks off something in your head and you begin to think a little differently and that may spark off someone else and discussions like that can grow arms and legs.

NQST5: ... It promotes higher order thinking but also it could be good because it promotes confidence in the individuals and it builds their social skills in either small groups or in larger whole class groups ... They are becoming more 
confident and from that they're then learning skills of higher order thinking and will be come more successful in learning.

Discussion as a guided transfer of knowledge to real-life contexts

This model of discussion involves the use of knowledge already gained in the class to help solve an issue with a real-life context, using generalisations of knowledge acquired in school to help resolve an unfamiliar problem. This involves the teacher guiding the discussion in order that the pupils might consider how their school knowledge could be used in their own life. The act of discussion allows the pupil to make connections between what they have learned in school to their own life in ways that other pedagogical approaches may not. Some teachers see this conceptual model of discussion as a way of preparing pupils for situations beyond the school boundaries as exemplified by Experienced Science Teacher participant 1 as follows.

ExST1: They are having to do projects and discussions in front of their peers or adults or whatever. You know that can be a worrying experience because we have had pupils before who have been going for interviews for medicine or veterinary [medicine] and it's a high level interview but they don't have the social skills to be able to interact and show people what their actual understanding of the knowledge is, so I think it's important as well as making sure they have the academic side that they have to be able to have the confidence to be able to represent what they actually know, because it can really pull them down in a situation were it is quite competitive like that. They need to be able to feel confident in themselves to be able to express their opinions.

This extract illustrates the need for pupils to be able to show their understanding in an academic sense in addition to the social and interpersonal sense. ExST1 suggests that this ability to take knowledge gained within the school environment out into the real life context is an important part 
of pupils' development in intellectual and social terms. This suggests that this model is closely linked to the model of discussion for democratic citizenship which follows. In a sense it is but, in the case of discussion of controversial socio-scientific issues within the science classroom, which also fits into this model, it is also different. Particularly since the knowledge gained from within the science curriculum, when discussed in this context, becomes more real. Issues such as embryonic stem cells research and the therapeutic use of stem cells presents the scientific theory within a social context, which could allow the pupils involved in the discussion to empathise with the people within the situation as presented, allowing pupils to see the effect that science can have on people's lives. However, some teachers indicated that pupils find this type of discussion difficult.

\begin{abstract}
ExHT3: In geography a lot of the stuff that we discuss is about things that surround them (the pupils), so we assume that they have seen a lot of the things that we are discussing ... The majority of the kids have an understanding of what you're talking about ... They are happy to give you factual information but when it comes to opinions, they are not so keen on doing that.
\end{abstract}

These types of discussion require the pupils to develop higher order cognitive processes in connection with the issue under debate. This requires cognitive effort and is seen as essential to the success of this model.

ExHT3: Pupils have to participate for a good discussion to take place; they need to be motivated to be involved in the discussion.

The use of these thinking skills should increase pupils' motivation to learn more about the issue, thereby resulting in a deeper understanding of the issue being talked about, allowing pupils to recognise the connections between topics and concepts rather than the simple comparison of facts. However, the issue itself can also be a motivating factor since some pupils may have a pre-existing 
interest in an issue or, in the case of medical matters, they may have first hand family experience of an issue to put forward.

\section{Discussion as practice for democratic citizenship}

Classroom discussion is a powerful pedagogical tool for the practice of oral communication skills, listening skills and general behaviour in social and cultural terms. Therefore, in this model the pupils practise skills such as listening skills, communication skills and social skills, and manners such as turn-taking, allowing others time to express their views without interruption. This kind of dialogue allows the pupils to practise the process of discussion itself. The following comments by Experienced Science Teacher participant 1 and Experienced Humanities Teacher participant 6 express the view that this model sees the practice of such skills as essential tools for participation as a citizen within a democratic society:

ExST1: I think that you need to develop social skills in pupils so that they can go outside a school and have a discussion about any topic and be able to use the knowledge that they've got but be able to have the social skills, as I say, to listen to other people and to value other people's opinion even if it's not exactly the same as their own because for some pupils that is a difficult thing for them to do... They need to be able to feel confident in themselves to be able to express their opinions.

ExHT6: For me discussion is a really useful tool for learning... I tend to drift, listen or I'll take part ... You encourage them to engage in the discussion by moderating it properly. I use it because the kids get to hear other people's opinions and in this day and age, in general in society, people just don't want to listen to other people's opinions because they have got their own and that's it. They are happy to force their opinion down your throat but will not listen, so as a 
side issue you have to teach the kids that someone may have a different opinion from you but that doesn't mean that they're wrong.

These quotations exemplify the feeling among this group of teachers that discussion can also be a learning outcome in its own right. Engaging in discussion involves a social element that is not necessarily used just to teach subject-specific content. In these terms, discussion is a skill in itself and as such requires practice. This model is, in many respects, central to all the others, in that without the communication skills or the ability to listen to other people's views, opinions and beliefs, discussion is likely to fail. However, one must differentiate what is meant by the terms fact, opinion, and belief. A belief could be described as an authoritative statement that has not been subjected to testing or may be incapable of being tested, where the belief relies on anecdotal evidence and the power of (perceived) authority. On the other hand, a fact can be a statement of actuality or occurrence which can be measured and reproduced, where there is no known or current evidence that casts doubt upon its truthfulness. Facts are therefore said to be 'beyond doubt', although new evidence may emerge in the future to question their accuracy. An opinion can be a statement of belief, judgement or a feeling which shows one's thinking about a subject. Where based on facts, opinions can be logical extensions of thoughts or hypotheses which are tentative and potentially subject to testing and revision over time. It is interesting to note that the science teachers' emphasis in discussion lay towards the development of social skills, whereas the humanities teachers' emphasis lay towards the development of thinking skills, the exposure to multiple perspectives and the formation of personal opinions.

\section{Teachers' comfort levels using discussion of controversial socio-scientific issues}

'Comfort level' in this context refers to the level of ease that each teacher feels using socioscientific discussion as part of their repertoire. Teachers' comments were assumed to reflect their personal views and feelings towards the issues in question. When asked how comfortable they felt 
discussing issues which arise from contemporary science such as controversial socio-scientific issues, there was a mixed response. For example, in the experienced science teacher group all of the teachers expressed the view that they were comfortable discussing such issues. However, they then followed this comment with a proviso such as "it depends on the topic" or "I have no problem with that at all but on occasion when you have to discuss these issues it's all of a general nature" These comments suggest that the experienced science teachers are not as comfortable discussing controversial socio-scientific issues as they say. One Experienced Science Teacher participant 1 commented as follows:

ExST1: I would say that I would like to feel more comfortable than I actually am. I do like having discussions in science but there tends not to be time to do it. I have been teaching nine years now and for the time that you have to take in delivering learning outcomes in class, it's not something you know, you're in your comfort zone, me talking to the pupils and then we do a quiz or a test and a lot of the time it's not involving their opinions, it's me telling them facts and then maybe finding some sort of fun way of learning. But I would not say that the majority of my teaching has been taken up discussing in-depth any science issues, maybe some wee facts and things during lessons, but I would not say there has been an appropriate amount of time spent on it so, I would say that certainly it is something that I have not had a lot of experience doing, then I would feel a wee bit apprehensive about doing it, but certainly it's something I am quite open to doing.

This comment extends the findings of recent Scottish research concerning the discomfort of Scottish Biology teachers concerning discussion (Author, 2004; Author, 2006). Of the twelve science teachers questioned in this study, only one commented that they were not comfortable 
discussing socio-scientific issues, whereas eleven of the teachers said that they were comfortable. However of these, nine said that this depended on their level of subject knowledge and eight said that this depended on the issue being discussed. Only two science teachers (ExST5 and NQST2) claimed to be very comfortable discussing such issues. Each of these teachers suggested that:

ExST5: I keep abreast of topical items so I don't have any qualms about broaching any new subject with them.

NQST2 suggested that because she was interested personally in such issues, she felt very comfortable as this excerpt from her interview transcripts shows:

NQST2: I think probably because I'm interested in these things I feel comfortable in that it's because it's things that I feel are important; it's not just about teaching a curriculum; it's about awareness of what's going on around us and I think that the kids have to be aware of these things.

Interviewer: Do you think say, if we were to change the issue, and I was to ask you to discuss the potential risks of mobile phone technology. How comfortable would you feel about going outside your subject knowledge?

NQST2: I mean if you were talking about if, I had time, are you talking about going and doing it without any prior knowledge?

Interviewer: No, how would you feel if it was coming up to that part of a course?

NQST2: I would have no issue at all, not at all, I'd just go and prepare and I would make sure I was prepared and I knew the issues that were currently on the go. Definitely, I wouldn't have any problem with that at all.

Interviewer: No issues at all? 


\begin{abstract}
NQST2: I think the only issue might be... it depends on the class make-up. If it's a particularly challenging class that may limit discussion and maybe how far I would like to take it, whether I would like to have a lesson that's primarily a discussion, that would limit it.
\end{abstract}

In this excerpt, NQST2 suggests that discussion of such issues is not something that she is particularly uncomfortable doing, provided that she has the time to prepare and assimilate the knowledge if she is not familiar with the subject matter. This could be interpreted in the following terms: that as long as the teacher has the subject knowledge and is aware of some of the key arguments within the area to be discussed then s/he is comfortable discussing such controversial socio-scientific issues. This line of thought could also be interpreted that as long as teachers know more about the subject being discussed than their pupils then they feel comfortable.

In addition, it could be argued that science teachers may shy away from discussion of socioscientific issues due to a lack of subject knowledge about the issue being discussed. Furthermore, that as such issues tend to emerge at the forefront of contemporary science it could be argued that it is unreasonable to expect science teachers to keep up with new emerging science sufficiently to be able to discuss such issues, especially if the science relevant to such issues is particularly new and contestable. This train of thought leads to a number of questions such as: Is this view a viable reason not to discuss such issues? Do discussions of socio-scientific issues require in-depth subject knowledge? Is this a view shared by humanities teachers?

In order to answer these questions, the experienced humanities teachers were asked how comfortable they felt when discussing issues with some scientific content. Of the six humanities teachers interviewed, four of them indicated that they felt very comfortable discussing issues with 
significant science content. ExHT1 suggested that in medical ethics they deal with a large level of scientific content:

\begin{abstract}
ExHT1: In $4^{\text {th }}$ year we've got medical ethics which very much has quite a big scientific component in the sense of looking at genetic engineering and embryo research. On those sorts of issue, they do have a basic understanding of what the actual facts are and have a sense about that but, at the same time, we try not to focus on that too much, in getting too involved on what the actual science is because it is the moral perspective we are looking at it from.
\end{abstract}

This comment suggests that the science involved in such an issue, while important, is only one perspective and that the other perspective which impinges on such issues allow people to engage in discussion. ExHT5 suggests that "It's not really a scientific question; it's more of a philosophical, ethical, moral type of question". Furthermore, ExHT6 suggests that he is comfortable even when his knowledge of the subject is not deep:

ExHT6: It depends: nobody likes to go outside their comfort-zone, so I would feel comfortable about it if I had some sort of knowledge of it but I would not be afraid for the kids who know more about it to take the lead. Just because I don't know much about a topic, doesn't mean I won't have a discussion about it at all because if some of the kids know more about it then brilliant, I'll learn something. If you don't like learning then you shouldn't be a teacher.

This brings us back to the issue of control of the discussion. It appears that humanities teachers see a potential for discussion, regardless of the teacher's subject knowledge; and that any issue is open for discussion since it is the perspectives through which the discussion is conducted that are 
important, not just the objective facts pertinent to the issue being debated. Humanities teachers seem to be happy to let their pupils lead discussion and are open to new perspectives.

The view of this group of humanities teachers is that a lack of subject knowledge is no hindrance to discussion of any issue, even issues with a scientific content. In addition, these humanities teachers do not feel that they need to know more than their pupils when initiating discussion as they are comfortable with them taking the lead. Furthermore, while they see subject knowledge as an important part of any dialogue, when discussing socio-scientific issues they see the science as only one perspective, thus they feel more comfortable when talking about such issues because they are comfortable with the other perspectives (such as the moral, ethical, social, economic and political) and place the focus of the discussion on those perspectives.

\section{Discussion}

The findings gained from this study have reflected usefully upon the three research questions posed at the start of this article, that is the possible differences between science and humanities teachers in their understandings of discussion, its purposes, and the extent of their (stated) professional comfort in using it as a pedagogical strategy. In this final section we reflect on all three issues, relating our remarks to the current literature on the management of classroom discussion and the difficulties (and successes) articulated by this group of teachers.

\section{Differences in emphasis}

As noted in the introduction, to date, no studies have been conducted into the question of whether science teachers hold a poor grasp of the pedagogy of discussion when compared to those held by their humanities colleagues. What our data show is that this group of science teachers hold equally complex conceptual models of discussion when compared to their humanities colleagues. However, there are differences in emphasis between the experienced science teachers, the newly qualified science teachers and the experienced humanities teachers as to the purpose served by it. When 
compared to experienced science teachers, fewer newly qualified science teachers mention that discussion is useful for the development of social skills, confidence, communication skills, exposure to multiple perspectives and the assessment of knowledge. However, more of the newly qualified science teachers stress that discussion helps to develop thinking skills. When compared to the experienced humanities teachers, this group of experienced science teachers emphasise discussion for the development of social skills, confidence and communication skills more frequently. However, all of the humanities teachers indicated that discussion is used for the development of thinking skills with more saying that it helps expose pupils to multiple perspectives useful to the formation of personal opinions than did experienced science teachers.

These differences suggest that this group of science teachers' emphasis for discussion is centred on the development of social skills, communication skills and listening skills (discussion as an outcome). To achieve this they would tend to use discussion as teacher mediated discourse and for the practice of democratic citizenship; whereas the humanities teachers' emphasis is centred on the development of reasoning skills and exposure of pupils to multiple perspectives for the development of personal opinion. They operate with discussion as open-ended inquiry and to develop reasoning skills (discussion as a method of instruction). In general, this group of teachers see discussion as both a learning outcome to be practised and as a teaching method for transfer of curricular content knowledge. Science teachers do tend to see discussion more as an outcome to be practised whereas humanities teachers see discussion more as a teaching method to promote transferable knowledge.

\section{Developmental progression?}

How the five conceptual models of discussion fit together is an interesting question. It could be suggested that discussion as teacher-mediated discourse is a starting point for the practice of discussion for democratic citizenship, since the development of social skills, listening skills, 
communication skills and argumentation skills must first be acquired as a prerequisite to the engagement in open-ended inquiry for the purposes of developing reasoning skills and the transfer of knowledge to real-life contexts. It could be further suggested that these models form a developmental progression through which pupils must journey in order to develop and practise the necessary behavioural characteristics and cognitive skills which enable them to acquire the skills required for discussion within a democratic classroom.

Figure 1 illustrates how these conceptual models of discussion may interact together. All forms of discussion within the classroom are to varying degrees, teacher-mediated. Normally it is the teacher who sets the parameters and context for debate and it is generally the teacher who initiates the first exchanges within any kind of discussion. What makes discussion open-ended inquiry for the development of reasoning skills, as well as a guided transfer of knowledge, is the willingness of the teacher to allow pupils to take control of the dialogue within differing contexts. It could be suggested that open-ended inquiry requires the teacher to relinquish most of the control of the discussion and, as such, would be the most difficult of all the models for teachers to manage.

\section{[Insert Figure 1 about here]}

It is fair to say from the tone of ExHT6's last comment that, at present, the pupils that he has encountered lack the prerequisite listening skills and good manners of open-mindedness and willingness to accommodate differing views. This view was shared by the majority of the teachers within this study. However, one teacher's view showed the fragile nature of teaching using discussion in science as a result of a perceived lack of social, communication and listening skills.

ExST5: In my experience, pupils, especially young pupils at this age group (1314 years), just don't have the decorum, that sustained decorum required for a viable discussion. I have tried it plenty of times in PSE [Personal and Social 


\begin{abstract}
From this comment, it is clear that if science teachers are to engage in discussion within their classrooms, they must realise that it is predominantly an oral endeavour. Given that oral language weaves the very fabric of classroom culture, any attempt to develop the use of discussion within science education requires a major alteration to the classroom culture. Merely planning 'to do' a discussion once or twice a term is insufficient preparation for the practice of the 'decorum' that is expected of pupils.
\end{abstract}

As suggested earlier, teacher-mediated discussion is the first step for the acquisition and practice of social, communication and listening skills by pupils. Thus a teacher-centred lesson ultimately must be the starting point from which the teacher builds the pupils' confidence, social, communication and listening skills to the point where the teacher can begin to allow them to step forward to find their own position. The issue here is ultimately about control. Teachers must first learn to release control of the discourse in their classrooms in order to allow pupils to realise their potential and, by extension, increase their participation within a debate.

\title{
Shift in style and approach
}

As Osborne et al. (2002) point out, science teachers generally adopt a style which is autocratic, closed and authoritative in nature, where the normal practice does not provide opportunities for interpretive and open discussion. Teachers tend to deal in well-established facts which are not open to question or interpretation. 
It is our contention that teachers tend to perceive that they are under pressure to manage behaviour and cover course content and, as a result, they dominate the oral discourse of the classroom, while pupils in general accept this discourse as part of the ethos of the classroom and accordingly assent to a curtailment of their role within the discourse. It is the alteration of this position, particularly the roles of the pupils and the teacher within discussion, especially in the science setting, that must be tackled if classroom discussion is to be encouraged and if pupils' development as culturally aware, critical thinkers is to be nurtured.

It is encouraging to note that this group of teachers did not see recitation or more specifically Initiation, Response and Feedback discourse as discussion. This is in contrast to the findings of Larson (2000), who found that American Social Science teachers saw recitation as a viable type of discussion. The recitative-style of classroom discourse has been described as the pedagogical opposite of discussion, in terms of its purposes and intended outcomes (Bridges, 1987; Bridges, 1979; Dillon, 1990; Dillon, 1994; Dillon, 1984; Henning, 2008).

How teachers choose which model to use (assuming they become explicitly familiar with the five types of discussion) depends on the context, aims and learning objectives of the lesson. How these interact is important, as they form a developmental pathway which becomes increasingly complex in terms of the teaching skills required to manage them and the confidence required by both teacher and pupils in fulfilling their respective roles. The classroom norms of each teacher impacts on the classroom culture experienced by pupils, therefore, if the teacher's normal classroom practice is autocratic and closed in terms of the dominant discourse, shifting from that norm towards a less autocratic, more open discourse could be difficult.

Research focusing on how science teachers manage argumentation within socio-scientific discussion indicates that the teacher plays a pivotal role by shaping the pattern of typical exchanges within the discourse and, through the use of questioning, controls the quality and direction of the 
argumentation pattern within the discussion (McNeill \& Pimentel, 2010; Osborne, Erduran, \& Simon, 2004; Simon et al., 2006). A natural inference from these studies is that teachers need to understand how their questioning during socio-scientific discussion affects the discourse. In addition, McNeill \& Pimentel (2010) suggest that increased use of open-ended questions plays a key role in supporting students' arguments in terms of providing evidence and reasoning for their claims and by encouraging greater dialogic interactions between students, this type of exchange being akin to a Socratic dialogue. However, there is little research offering support to science teachers by way of a working model of how to successfully manage socio-scientific discussion within their practice. Our own current research into the management of small group discussion within school science may in time yield fresh insight as to how science teachers might facilitate the required shift in their role within discussion from that of disseminator to that of facilitator. In the absence of a working model, further research into how science teachers manage argumentation within socio-scientific discussion would help to build their confidence in the use of discussion as a method of instruction.

\section{Confidence, comfort and control}

The science teachers interviewed in this study claimed that they would be comfortable discussing controversial socio-scientific issues which, on the face of it, seems to contradict recent research findings (Author, 2004; Author, 2006; Levinson et al., 2001) that science teachers are uncomfortable leading such discussions. However, the reported comfort level of the science teachers in this study was conditional, with the main conditions being the level of knowledge and understanding of the teacher (as well as the personal interest of the teacher) in relation to the issue being discussed. This indicates that these science teachers are far less comfortable than they claim. A number of science teachers also commented that there were issues that they would not discuss for 
personal reasons, with one teacher suggesting that he would avoid discussions that put him outside his 'comfort zone'.

It could be argued that science teachers are used to dominating the classroom discourse through their input and control of the content knowledge being transferred during lessons. A number of science teachers did report that they would prepare extensively so that they knew the relevant facts required for discussion of socio-scientific issues prior to delivery of these lessons. This could be viewed that, for these science teachers, it is important that they know more about an issue or topic than the pupil. One might further argue that the status of the Science teacher as an authoritative and knowledgeable figure within the classroom discourse shapes his/her feelings of comfort. It is the loss of comfort and, by extension, control of the classroom discourse which, one may speculate, leads to science teachers' neglect of discussion within their practice. One may further speculate that such loss of comfort and control might potentially make them fearful of a loss in control of class discipline. At the risk of over-generalising, one can speculate that most science teachers do see a loss of control of classroom discourse as a loss of class control and discipline.

However, the humanities teachers in this study were less fearful of a loss of control of the classroom discourse since they are happy to allow pupils to take control of that discourse. For them, relinquishing control of the discourse does not imply a loss of control of the class discipline. This group of humanities teachers see a clear distinction between who dominates the classroom discourse and who is in control of the class. It could be argued that the main difference between humanities teachers' views on the use of different models of discussion and those of science teachers is confidence. Science teachers lack confidence in using discussion, as it requires them to give control of the discourse over to pupils and the fear of a consequential loss of control of discipline holds them back. 
This train of thought requires one to consider the role played by the teacher. This group of humanities teachers believe that their leadership of the discussion is critical to the success of that discussion. It should be noted that this does not imply that the humanities teacher wishes to control all of the interactions within a debate. Their leadership of the dialogue is dependent on the conceptual model or level of discussion they wish to adhere to. ExHT6 exemplifies this suggestion as he likes to drift in and out of the discussion in his class, taking part in it or encouraging others by moderating it. This type of interaction between the teacher and the pupils clearly shows that ExHT6 is in control of the discipline and conduct of the lesson but not the discourse.

The difference in emphasis between science and humanities teachers suggests that for science teachers to utilise the full range of discussion models available to them, they need to shift their emphasis towards the position held by humanities teachers, if the promotion of discussion in science, required under $C f E$, is to be fruitful in terms of pupil development towards scientific literacy and, more particularly towards some achievement of the four capacities of $C f E$ (confident individuals, effective contributors, responsible citizens and successful learners).

Science teachers' emphasis on discussion as an outcome belies the fact that many science teachers define work done by pupils in terms of a piece of concrete work (usually written) on a page in a notebook. Discussion, in general, produces little in the way of written evidence that it has occurred, therefore it is difficult for some science teachers to judge the success of such discussion in terms of knowledge acquisition. In other words, science teachers may see the learning process in science as a reproductive act (teacher tells pupil, pupil repeats back to teacher in a written form) rather than a generative process (teacher poses a question, pupils give multiple responses based on their understanding at that point in time). Science knowledge is tentative in nature and open to modification over time when new evidence emerges from experimental research, thus science knowledge is not fixed but is emergent (or generated) over time. 
Scientific knowledge is often portrayed by school science as fixed and therefore not open to question or revision. Some science teachers might even see the scientific knowledge that they teach as a body of facts to be assimilated over time for the purposes of passing an end-stage exam. This often leads pupils to gain knowledge without understanding rather than a deep conceptual understanding of how the knowledge fits into a given context.

Discussion works best when a pupil's conceptual understanding of a topic is challenged either by the teacher (possibly using a Socratic method) or by his/her peers. Such challenge leads to a cognitive conflict (disequilibrium) which may result in the pupil's thinking being either modified, in the light of views expressed during the discussion, confirmed or even completely overturned (Strike \& Posner, 1982; Posner, Strike, Hewdon \& Gertzog, 1982; Vosniadou \& Brewer, 1987). Meta-cognition by pupils exposes their thinking to scrutiny in the light of their personal experience within the discussion and allows them to improve and develop their own thinking, so that in future they become better at evaluating their own and others' arguments. Humanities teachers use discussion in this way, seeking to challenge pupils' thinking, perceptions and attitudes at a deeper level, since they are typically dealing with opinions and perspectives rather than objective facts. This in many respects forces humanities teachers to adopt a less autocratic style in the absence of an absolute answer to many of the questions that they pose.

\section{Content and contextual knowledge}

With respect to the relationship between what learners know about relevant science ('content knowledge') and their skills in debate concerning socio-scientific issues ('argumentation'), Sadler and Donnelly (2006) note the general paucity of research in the field, and the lack of consensus among the few studies which have tackled it. In their own empirical investigations, which figured genetics topics and genetic engineering issues, they found little evidence of the application of content knowledge among the students at a (US) urban high school. Contrasting this with more 
positive findings from an earlier study (Sadler \& Zeidler, 2005), the authors reason that students need to possess adequate context knowledge, as well as content knowledge (c.f. Barnett and Hodson, 2001); in this case they need to be familiar with basic ideas about gene therapy, cloning and what families face in circumstances involving the prospects of genetic engineering. These researchers further reason that 'Understandings of content and context are interdependent' (Sadler \& Donnelly, 2006). They argue that in high school teaching, student reasoning and argumentation will be improved through a more explicit focus on socio-scientific discussions involving scientific applications; argumentation skills require practice.

If science teachers are to incorporate more debate in their teaching and are to develop approaches useful for the discussion of controversial socio-scientific issues in particular, as part of their effort towards the development of scientific literacy, a paradigm shift is required in the way that they view the nature of science, the aims of science education and their role within the delivery of the curriculum. This will require them to view scientific knowledge in a far less rigid manner than at present; to change their lesson delivery to include approaches which foster more genuine forms of open inquiry; to view science education as a vehicle for the promotion of scientific literacy rather than as a preparatory road to specialism for the few; and to end the present culture of teaching only that which is to be externally examined.

\section{References}

Alvermann, D. E., O'Brien, D. G., \& Dillon, D. R. (1990). What Teachers Do When They Say They're Having Discussions of Content Area Reading Assignments: A Qualitative Analysis. Reading Research Quarterly, 25, 296-322.

Author, (2004)

Author, (2006) 
Barnett, J., and Hodson, D. (2001). Pedagogical Context Knowledge: Toward a Fuller Understanding of What Good Science Teachers Know. Science Education. 85, 426 453.

Bennett, J., Hogarth, S., Lubben, F., Campbell, B., \& Robinson, A. (2010). Talking Science: The research evidence on the use of small group discussions in science teaching. International Journal of Science Education, 32, 69-95.

Bridges, D. (1979). Education, Democracy and Discussion. Windsor: NFER Publishing.

Bridges, D. (1987). Discussion and questioning. Questioning Exchange, 1, 34-37.

Brookfield, S. D. \& Preskill, S. (2005). Discussion as a way of teaching: Tools and techniques for democratic classrooms. San Francisco; CA: Jossey-Bass.

Clark, C. M. \& Peterson, P. L. (1986). Teachers' thought processes. In M.Wittrock (Ed.), Handbook of research on teaching (3rd ed., pp. 266-298). New York: Macmillan.

Cross, R. \& Price, R. (1996). Science teachers' social conscience and the role of teaching controversial issues in the teaching of science. Journal of Research in Science Teaching, 33, 319-333.

Dawson, V. M. \& Venville, G. (2010). Teaching Strategies for Developing Students' Argumentation Skills about Socioscientific Issues in High School Genetics. Research in Science Education, 40, 133-148.

Dillon, J. T. (1990). Conducting discussions by alternatives to questioning. In W.W.Wilen (Ed.), Teaching and learning through discussion: The theory, research and practice of the discussion method (pp. 79-96). Springfield, IL: Charles C. Thomas. 
Dillon, J. T. (1994). Using Discussion in Classrooms. Buckingham: Open University Press.

Dillon, J. T. (1984). Research on questioning and discussion. Educational Leadership, 42, 51-56.

Farmer, S., Finlayson, M., Kibble, R., \& Roach, A. (2006). The ROSE Survey in Scotland - An Initial Report: Views of Secondary 3 Pupils on the Relevance of Science Education. Glasgow: UK: STEM-ED Scotland.

Henning, J. E. (2008). The Art of Discussion-Based Teaching: Opening up Conversation in the Classroom. New York: Routledge.

Hess, D. E. (2004). Discussion in social studies: Is it worth the trouble? Social Education, 68, 151155.

Hodson, D. (1999). Building a Case for a Socio-cultural and Inquiry-Oriented View of Science Education. Journal of Science Education and Technology, 8, 241-249.

Hodson, D. (2003). Time for action: science education for an alternative future. International Journal of Science Education, 25, 645-670.

Larson, B. E. (2000). Classroom discussion: a method of instruction and a curriculum outcome. Teaching and Teacher Education, 16, 661-677.

Levinson, R. (2001). Should controversial issues in science be taught through the humanities? Schools Science Review, 82, 97-102.

Levinson, R. (2003). Teaching socio-scientific issues: challenges in traversing domains. In Paper presented at the ESERA Conference, Noorwijkerhout, The Netherlands, August 19-23, 2003. 
Levinson, R. \& Turner, S. (2001). Valuable Lessons Engaging with the Social Context of Science in Schools London: The Wellcome Trust.

McNeill, K. L. \& Pimentel, D. (2010). Scientific Discourse in Three Urban Classrooms: The role of the teacher in engaging high school students in argumentation. Science Education, 94, 203-229.

Millar, R. \& Osborne, J. (1998). Beyond 2000: Science Education for the Future. London: King's College.

Nystrand, M., Gamoran, A., \& Carbonaro, W. (1998). Towards an Ecology of Learning: The Case of Classroom Discourse and Its Effects on Writing in High School English and Social Studies. Albany, NY: Center on English Learning \& Achievement.

Osborne, J., Duschl, R., \& Fairbrother, R. (2002). Breaking the Mould? Teaching Science for Public Understanding London: The Nuffield Foundation.

Osborne, J., Erduran, S., \& Simon, S. (2004). Enhancing the Quality of Argumentation in School Science. Journal of Research in Science Teaching., 41, 994-1020.

Oulton C, Dillon J, \& Grace MM (2004). Reconceptualizing the teaching of controversial issues. International Journal of Science Education, 26, 411-423.

Parker, W. C. \& Hess, D. (2001). Teaching with and for discussion. Teaching and Teacher Education, 17, 273-289.

Ravetz, J. (2002). Reflections on the new tasks for science education. Unpublished Evidence submitted to the House of Commons Committee for Science and Technology.

Reiss M (1999). Teaching ethics in science. Studies in Science Education, 37, 115-140. 
Sadler, T. D. \& Donnelly, L. A. (2006). Socioscientific Argumentation: The effects of content knowledge and morality. International Journal of Science Education, 28, 1463-1488.

Sadler, T. (2004a). Informal Reasoning Regarding Socioscientific Issues: A Critical Review of Research. Journal of Research in Science Teaching, 41, 513-536.

Sadler, T. (2004b). Moral and Ethical Dimensions of Socioscientific Decision-Making as Integral Components of Scientific Literacy. Science Educator, 13, 39-48.

Sadler, T. \& Zeidler, D. (2005). The Significance of Content Knowledge for Informal Reasoning Regarding Socioscientific Issues: Applying Genetics Knowledge to Genetic Engineering Issues. Science Education, 89, 71-93.

Simon, S., Erduran, S., \& Osborne, J. (2006). Learning to teach argumentation: Research and development in the science classroom. International Journal of Science Education, 28, $235-260$. 


\section{Appendix \\ Biographical notes about the teachers interviewed in this study.}

\section{Experienced Science Teachers}

ExST1 is a 31 year old female Principal Teacher of Pupil Support who teaches Biology. She has been teaching for nine years. She has a Bachelor of Education (Honours) degree in Biology and Education. She teaches S1 and S2 mixed ability Science classes as well as S3/S4 Standard Grade Biology and S3/4 access 3/Intermediate 1 Biology classes as well as S5 Intermediate 2 and Higher Human Biology classes. In addition to teaching Biology she has considerable experience of teaching S1 to S6 Personal, Social and Health Education (PSHE) classes.

ExST2 is a 38 year old female Biology teacher who has taught for eight years. She has a Bachelor of Science (Honours) degree in Immunology and a Postgraduate Certificate in Education (PGCE Secondary) in Biology with Science. She teaches S1 and S2 mixed ability Science classes as well as S3/S4 Standard Grade Biology and S3/4 access 3/Intermediate 1 Biology classes as well and S5 Intermediate 2 and Higher Human Biology classes. In addition, ExST2 also teaches S6 Advanced Higher Biology as well as S1 to S6 PSHE and has a pupil support role within the school.

ExST3 is a 50 year old male Principal Teacher of Biology who has been teaching for thirty years. ExST3 has a Bachelor of Education (Honours) degree in Biology and Education. In his time within this school he has had various responsibilities such as assistant principal teacher of guidance and acting assistant head teacher. ExST3 currently teaches S1 and S2 mixed ability Science classes. He also teaches S3/S4 Standard Grade Biology classes as well as S3/4 Access 3/Intermediate 1 
Biology classes. In addition ExST3 also teaches S5 Intermediate 2 Biology and S5/6 Higher Human Biology classes as well as an S5/6 Higher Psychology class.

ExST4 is a 31 year old female Biology/Chemistry teacher who has been teaching for seven years. She has a Bachelor of Science (Honours) degree in Biochemistry and a PGCE (secondary) in Biology with Science and an Additional Teaching Qualification (ATQ) in Chemistry. She teaches S1 and S2 mixed ability Science classes as well as S3/S4 Access 3/Intermediate 1 Biology classes. In addition, she teaches S3/S4 Standard Grade classes in both Biology and Chemistry and teaches both S5/S6 Higher Human Biology and Chemistry classes. Furthermore, she teaches S1 to S6 PSHE classes.

ExST5 is a 45 year old male Biology/Gaelic teacher who has been teaching for twenty years. He has a Doctor of Philosophy degree in Biochemistry and a Bachelor of Science degree in Biochemistry as well as a PGCE (secondary) in Biology with science and an ATQ in Computing studies. ExST5 is a native Gaelic speaker with responsibility for teaching S1 and S2 Science in Gaelic as well as S1 to S6 Gaelic classes for Mathematics in addition to Higher Gaelic. ExST5 also teaches S1 to S6 PSHE classes in English.

ExST6 is a 60 year old Principal Teacher of Physics who has been teaching for twenty-five years. He has a Bachelor of Science (Honours) degree in Physics and Mathematics and a PGCE (secondary) in Physics with Science. ExST6 teaches S1/S2 mixed ability Science classes as well as S3/S4 Standard Grade Physics classes. In addition he also teaches S5/S6 Higher Physics and Advanced Higher Physics. 
ExST7 is a 43 year old female Physics teacher who has a Bachelor of Science degree in Physics and a PGCE (secondary) in Physics with Science and Mathematics. ExST7 teaches S1/S2 mixed ability Science classes as well as S3/S4 Standard Grade and Intermediate 1 Physics classes as well as S5/6 Intermediate 2 Physics. It should be noted that ExST7 did not take part in the semi-structured teacher interviews on discussion but was prepared to contribute to the teaching of the discussion of climate change and global warming using cooperative learning along with the post-lesson series semi-structured interview.

\section{Newly Qualified Science Teacher Background}

NQST1 is a 24 year old female Chemistry teacher who is in her second year of teaching. She has a Bachelor of Science (honours) degree in Chemistry with a Professional Graduate Diploma in Education (PGDE) in secondary education for Chemistry with Science. She teaches S1 and S2 mixed ability Science classes as well as S3/S4 access 3/Intermediate 1 Chemistry classes. In addition, she teaches S3/S4 Standard Grade Chemistry classes as well as S5 Intermediate 2 Chemistry classes. In addition, NQST1 teaches S1 to S6 PSHE classes.

NQST2 is a 23 year old female Biology probationary teacher. She has a Bachelor of Science (Honours) in Biochemistry and a PGDE (secondary) in Biology with Science. She teaches S1 and S2 mixed ability Science classes as well as S3/S4 access 3/Intermediate 1 Biology classes. In addition, she teaches S3/S4 Standard Grade Biology classes.

NQST3 is a 23 year old female Chemistry probationary teacher. She has a Bachelor of Science (honours) degree in Biochemistry with a PGDE (secondary) 
education for Chemistry and Biology with Science. She teaches S1 and S2 mixed ability Science classes as well as a S3/S4 Access 3/Intermediate 1 Chemistry classes. In addition, she teaches a S3/S4 Standard Grade Chemistry classes and in her probationary year is teaching a S5 PSHE class.

NQST4 is a 23 year old male Physics probationary teacher. He has a Bachelor of Science in Engineering and a PGDE (secondary) in Physics and Mathematics with Science. He teaches S1 and S2 mixed ability Science classes as well as S3/S4 access 3/Intermediate 1 Physics classes. In addition, he teaches a S3/S4 a Standard Grade Physics class

NQST5 is a 23 year old female Physics probationary teacher. She has a Bachelor of Science (honours) degree in Applied Physics with a PGDE (secondary) in Physics with Science. She teaches S1 and S2 mixed ability Science classes as well as a S3/S4 access 3/Intermediate 1 Physics class. In addition, she teaches a S3/S4 Standard Grade Physics class.

NQST6 is a 23 year old male Chemistry probationary teacher. He has a Bachelor of Science (honours) degree in Chemistry with a PGDE (secondary) in Chemistry with Science. He teaches S1 and S2 mixed ability Science classes as well as a S3/S4 Access 3/Intermediate 1 Chemistry classes. In addition, he teaches a S3/S4 Standard Grade Chemistry class.

Experienced Humanities Teachers.

ExHT1 is a 28 year old female Religious, Moral and Philosophy Studies teacher with six years teaching experience. She has a Master of Arts degree in Philosophy 
and a post-graduate diploma in Religious Studies and a PGCE (secondary) in Religious Education.

ExHT2 is a 45 year old male Religious, Moral and Philosophy Studies teacher with thirteen years teaching experience. He has a Bachelor of Arts degree in Media Studies, a Doctor of Philosophy degree in Religion and Film in American Culture and a PGCE (secondary) in Religious Education.

ExHT3 is a 28 year old male Geography/History teacher who has been teaching for seven years. He has a Bachelor of Art (Honours) degree in Geography, a PGCE (secondary) in Geography as well as an ATQ in History and Modern Studies. At the time of the interview he had just completed the first year of part-time study for a Master of Education degree.

ExHT4 is a 52 year old male Principal Teacher of History and Geography who has been teaching for thirty years, fifteen of which as principal teacher of History and Geography. He has a Bachelor of Arts degree in History and Education.

ExHT5 is a 57 year old male English teacher who has been teaching for thirtytwo years He has a Bachelor of Arts degree in English and Philosophy, a PGCE (secondary) in English and has a Master of Education degree in Professional Studies.

ExHT6 is a 30 year old male English teacher who has been teaching for seven years. He has a Bachelor of Arts (honours) degree in History and a PGCE (secondary) in English. 
Figure 1: Scottish Teachers' Conceptual Models of Classroom Discussion.

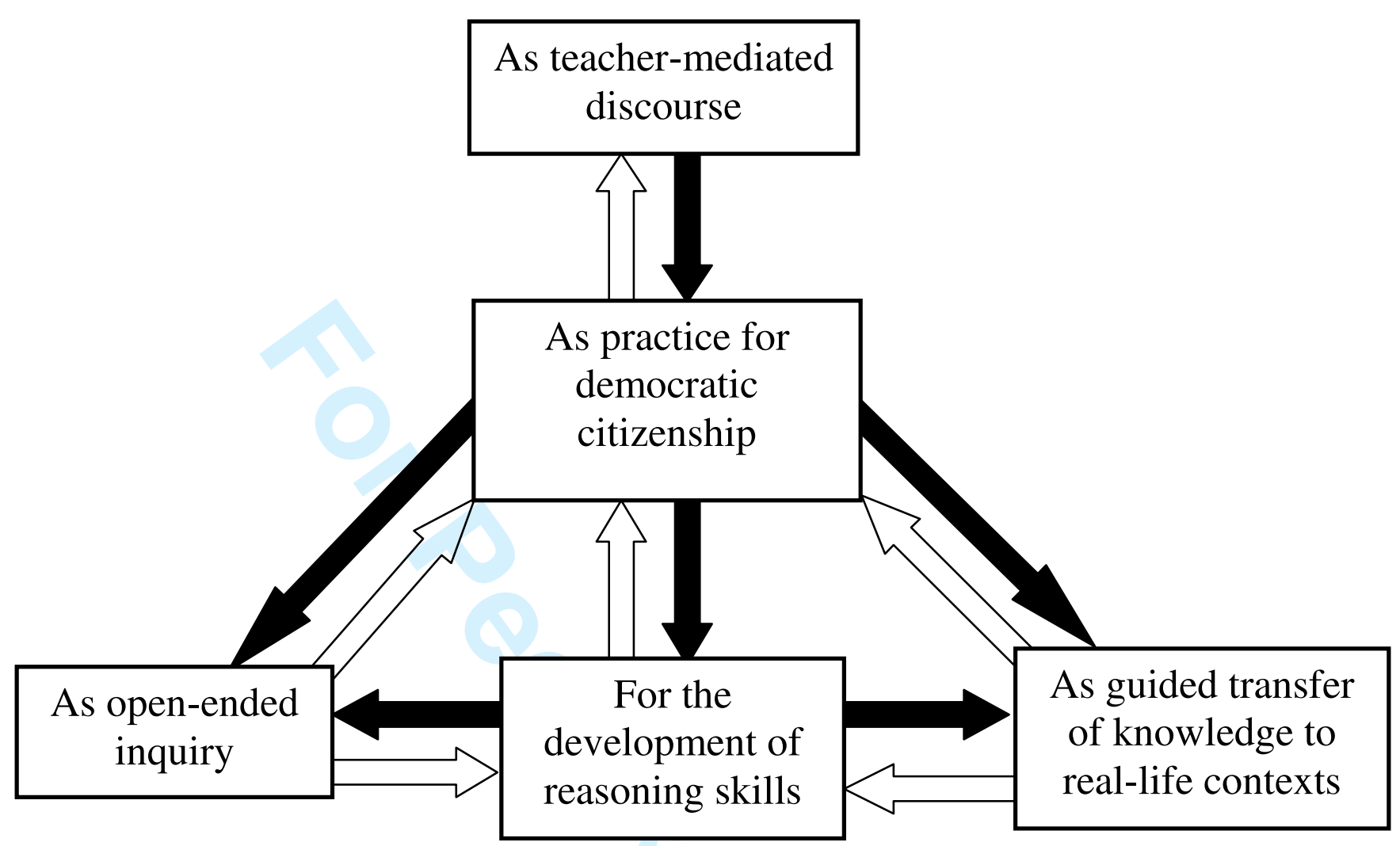


Table 1: Characteristic components of discussion as mentioned by teachers in their semi-structured interview.

\begin{tabular}{rcccc}
\hline & \multicolumn{3}{c}{ Proportion of Teachers who mentioned a characteristic } \\
\cline { 2 - 5 } Characteristic component of discussion & $\begin{array}{c}\text { Experienced } \\
\text { Science } \\
\text { Teachers } \\
(\mathrm{n}=6)\end{array}$ & $\begin{array}{c}\text { Newly } \\
\text { Qualified } \\
\text { Science } \\
\text { Teachers } \\
(\mathrm{n}=6)\end{array}$ & $\begin{array}{c}\text { Science } \\
\text { Teachers } \\
\text { Overall } \\
(\mathrm{n}=12)\end{array}$ & $\begin{array}{c}\text { Experienced } \\
\text { Humanities } \\
\text { Teachers } \\
(\mathrm{n}=6)\end{array}$ \\
\hline Development of social skills & 5 & 4 & 9 & 3 \\
Development of confidence & 4 & 4 & 8 & 3 \\
Development of communication skills & 4 & 1 & 5 & 3 \\
Development of listening skills & 3 & 2 & 5 & 3 \\
Development of thinking skills & 2 & 3 & 5 & 6 \\
Exposure to multiple perspectives & 3 & 2 & 5 & 4 \\
Assessment of knowledge & 2 & 1 & 3 & 1 \\
Formation of personal opinions & 0 & 1 & 1 & 3 \\
\hline
\end{tabular}

